\title{
The Role of Estrogen in the Treatment of Men with Schizophrenia
}

\author{
Jayashri Kulkarni ${ }^{1, "}$, Emmy Gavrilidis ${ }^{1}$, Roisin Worsley ${ }^{1}$, Tamsyn Van Rheenen ${ }^{1}$, Emily Hayes ${ }^{1}$ \\ ${ }^{1}$ The Monash Alfred Psychiatry Research Centre, The Alfred and Monash University School of Psychology, Psychiatry and Psychological Medicine, Melbourne, Australia \\ ${ }^{*}$ Corresponding author: Jayashri Kulkarni, Monash Alfred Psychiatry Research Centre, Level One, Old Baker Building, The Alfred Hospital, Commercial Rd, Melbourne 3004 , Australia. \\ Tel:+61-39076 6924, Fax:+ 61-39076 8545, E-mail: j.kulkarni@alfred.org.au.
}

Received: June 01, 2012; Revised: August 20, 2012; Accepted: September 28, 2012

\begin{abstract}
Schizophrenia is a debilitating and pervasive mental illness with devastating effects on many aspects of psychological, cognitive and social wellbeing. Epidemiological and life-cycle data point to significant differences in the incidence and course of schizophrenia between men and women, suggesting that estrogen plays a "protective" role. Adjunctive estrogen therapy has been shown to be effective in enhancing the treatment of schizophrenia in women. In men, consideration of estrogen therapy has been impacted by concerns of feminisation, however, clinical trials using estrogen to treat prostate cancer, bone density loss and even aggression in men with dementia or traumatic brain injury, show estrogen to be a safe and effective therapy. Findings do, however, suggest that further exploration of a therapeutic role for adjunctive estradiol treatment in men with schizophrenia is warranted. The development of the new estrogen compounds - Selective Estrogen Receptor Modulators (SERMs) which do not cause feminisation - opens up the possibility of using a different type of estrogen for a longer period of time at higher doses. Estrogen could therefore prove to be an important component in the treatment of psychotic symptoms in men with schizophrenia. This review explains the scientific rationale behind the estrogen hypothesis and how it can be clinically utilised to address concerns unique to the care of men with schizophrenia.
\end{abstract}

Keywords: Estrogen; Schizophrenia; Psychosis; Neuroprotection; Men; Selective Estrogen Receptor Modulators

\section{Background}

Schizophrenia is a psychotic illness characterised by a constellation of positive and negative symptoms, resulting in significant social and/or occupational impairment (1). In Australia, it is estimated that approximately 5 in 1000 adults suffer from a psychotic illness such as schizophrenia, with the prevalence being slightly higher in males than females (2). Although the prevalence is low in comparison to other psychiatric disorders such as depression and anxiety, the burden of disease for the individual and family plus the financial cost to the community are incredibly high and not to be underestimated (3). Additionally, a significant number of patients with schizophrenia do not recover with standard forms of pharmacologic treatment, or develop serious adverse effects that further debilitate their already poor quality of life. Therefore, safe and effective augmentation strategies need to be urgently identified and investigated. Adjunctive estrogen therapy could be one such strategy.

While the possible link between sex hormones such as estrogen, and schizophrenia was considered as early as the late 19th century by luminaries such as Kraepelin and Krafft-Ebing $(4,5)$ it is only in recent decades that extensive preclinical research has begun to substantiate this link. Animal and human studies have demonstrated the profound effects that sex hormones can exert in the central nervous system, including the neurotransmitter systems thought to underlie the pathogenesis of schizophrenia. Such research has led multiple authors (6-9) to propose that estrogen may therefore protect against schizophrenia, and in fact, clinical trials to date on the use of adjunctive estradiol therapy in women with schizophrenia have been promising $(10,11)$. This paper aims to explore whether adjunctive estrogen therapy could be an equally viable treatment option in men.

\section{Gender Differences in Schizophrenia Symptoms and Course of Illness}

Differences in the time course of schizophrenia between men and women underlies the 'estrogen hypothesis’ of schizophrenia (12). Although lifetime prevalence rates of schizophrenia in males and females are relatively

Implication for health policy/practice/research/medical education:

Schizophrenia is a serious and debilitating disease with significant social and economic costs to the individual, their family and society. New treatment approaches are needed to improve patients' quality of life and functioning above the current outcomes seen with existing treatments. Innovative adjunctive hormone therapies, such as estradiol and SERMs, may offer new opportunities to achieve improved outcomes in a broad population of individuals with schizophrenia.

Copyright @ 2013, Research Institute For Endocrine Sciences and Iran Endocrine Society; License Kowsar Ltd. This is an open-access article distributed under the terms of the Creative Commons Attribution License (http://creativecommons.org/licenses/by/3.0), which permits unrestricted use, distribution, and reproduction in any medium, provided the original work is properly cited. 
similar $(13,14)$, recent meta-analyses have demonstrated that the incidence of schizophrenia in men is actually approximately 1.5 times higher than in women $(15,16)$. More importantly, the average age of onset in men is considerably younger than for women: for males the mean age of onset is 26.5 years, whereas in females, it is 30.6 years (6). It is hypothesised that in women, estrogen may act as a psychoprotective agent both during the early stages of brain development and following pubertal increases in sex steroids. Estrogen action thus accounting for the lower incidence and later onset of schizophrenia in premenopausal females in comparison to their male counterparts (17).

First-episode late onset schizophrenia is more common in women than men (18), often occurring in women during the perimenopause, a time of fluctuating and eventually declining estrogen levels. This is again consistent with the notion that estrogen may offer women some protection against psychotic illness - a protection which is lost with the diminishing estrogen levels seen at the menopause. In some women, symptoms are also worse during the low-estrogen early-follicular phase of the menstrual cycle $(19,20)$. Marked differences in course, severity and expression of illness also exist between the sexes. Being diagnosed at a younger age, men often have not yet attained the same degree of social development as women at onset of illness (21). This combined with the observation that men tend to display significantly higher levels of adverse illness behaviours and substance abuse (22), contributes to the poorer social outcomes of men with schizophrenia. Furthermore, many authors report differences in symptomatology for males and females. For example, early studies found that men were more likely to experience negative and depressive symptoms than women, who were instead more likely to display symptoms of paranoia $(23,24)$. In a population study conducted by Dopfner and colleagues, conduct disorders, aggressive behaviours, antisocial personality traits and drug abuse were more often present in men (25). More recent, larger studies have demonstrated that in general, men experience a significantly more severe course of illness than women overall, exhibiting higher levels of psychopathology and disability, and lower levels of functioning, treatment adherence, response to antipsychotic medications and insight $(22,26)$. Limited insight in particular may lead to poorer outcomes for men as it can delay and impair treatment (27).

\section{Psychoprotective Properties of Estrogens}

Estrogens are neurosteroids with widespread genomic and non-genomic effects $(28,29)$. In men, estrogen in the form of estrone (E1) and estradiol (E2) is derived from the conversion of testosterone by the enzyme aromatase. Estradiol has a stronger affinity for estrogen receptors and is the isoform used in clinical practice.
The effects of estrogens on cognition and mood have been well established (e.g. (30-34)). Estrogen receptors are densely populated in areas of the human brain that control cognitive and emotional function. These include subcortical regions such as the hippocampus (memory) and amygdala (emotion) as well as a range of cortical areas involved in higher order functioning (35-38).

Estrogens modulate the neurotransmitters responsible for cognitive and emotional processes (39). For example, estrogens reduce dopamine receptor sensitivity and increase D2 receptor density in the striatum of ovariectomised rats, while also significantly enhancing serotonergic neurotransmission (40-43). Its effects on mental state are thought to occur via an influence on the availability of these mood-relevant neurotransmitters in the synapse (44-47). In particular, estrogens appear to have a protective effect on neurodegenerative disorders characterised by core cognitive dysfunctions including Parkinson's disease and Alzheimer's disease. The cardinal symptoms of Parkinson's disease are caused by dopaminergic cell death, yet estradiol appears to have an anti-apoptotic effect on dopaminergic neurons (48). Thus, increased estrogen availability in females may delay the onset of Parkinson's by increasing levels of striatal dopamine at symptom onset (49).

In Alzheimer's disease, neuropsychological function has also been linked with reduced dopamine activity (50). Estrogen use in both Parkinson's and Alzheimer's populations have however been associated with lower symptom severity, better cognitive functioning and greater independence in activity (50-54). Moreover, women with a history of estrogen use post menopause demonstrate reduced Alzheimer's risk and later disease onset (55, 56). Substantial reductions in estrogen levels have also been found in the postmortem brains of females with Alzheimers compared with age and gender-matched controls $(57,58)$.

To date, research into the effects of estrogens on cognition and mood has predominantly focused on women. Increased estrogen levels are associated with reduced negative affect and heightened wellbeing, as well as enhanced cognitive function including improved fluency, processing speed and better verbal and motor skills in healthy women (59).

The protective effect of estrogen in schizophrenia is well researched and is hypothesised to be the result of its neuroleptic-like effect on the dopamine system (19, 60-63). Dopamine overproduction is a pathophysiological feature of the illness and estrogen appears to blunt this effect by reducing dopamine receptor sensitivity and increasing the threshold for vulnerability $(64,65)$. Interestingly, neurocognitive and mood impairments are features of schizophrenia and other severe mental illnesses characterised by abnormalities in dopaminergic and serotonergic activity (66-75). Increased estrogen 
appears to have a positive effect on these symptoms and abilities. For example, in schizophrenic women during periods when estrogen levels are high, cognitive and positive symptoms have been found to decrease (76). Higher levels of estrogen have been associated with better executive function (77) and verbal and spatial memory (78) as well as decreases in psychotic symptoms $(11,62)$. Estrogen augmentation has also been found to be effective in improving mood symptoms in women suffering various depressive disorders $(31,32)$.

In men, the estrogen literature is less comprehensive and its effect on cognition and mood is not particularly well understood. Some research has demonstrated a relationship between higher estrogen levels and better cognitive performance in males (79-83). However evidence remains mixed, with other studies failing to find associations with disorders of cognition (84) and others still, reporting decreases in cognitive ability when estrogen levels are high (85-87).

Poor cognition and depressive symptoms have been found in men with low testosterone levels (88-93). Testosterone supplementation on the other hand, has been associated with improvements in these functions (94, 95) and is postulated to be neuro-protective in men with disorders characterised by cognitive dysfunction $(96,97)$.

Testosterone deprivation, which results in low estrogen levels, has been related to psychosis (98), deficits in spatial ability and memory (99) and increases in anxious and depressive symptoms (100). Improvements in spatial and verbal memory as well as executive integration have been observed in men receiving testosterone supplementation where estrogen levels in the testosterone treated groups were substantially increased $(95,101)$. Collectively these findings imply that the effect of testosterone on cognition and mood may well be due to estrogen.

In animal studies estrogen has been found to increase the density of serotonin binding sites in higher brain regions including the frontal cortex and has been implicated in the acquisition and improvement of spatial learning and memory (102-104). In human males, verbal memory improvements in those administered testosterone are negated by the coadministration with an aromatase inhibitor that prevents the conversion of testosterone to estrogen (105). These findings fit well with reports of better verbal memory performance in male to female transsexuals undergoing estrogen therapy when compared to those awaiting it, and better visual memory performance in men with heightened circulating estrogen levels compared to menopausal women $(106,107)$. Higher estrogen levels have also been associated with lower depressive symptoms in elderly patients of both sexes (108).

Estrogen supplementation in men is relatively rare, although it has been used in the treatment of prostate cancer and there are growing reports of its effectiveness in improving testosterone deficiency related verbal memory loss in men, reducing cardiovascular toxicity and male vasomotor symptoms, increasing bone density and improving quality of life $(93,109-111)$. In schizophrenia, estrogen levels in men tend to be low and estrogen augmentation may prove effective and have similar protective benefits for men as it does for women with the disorder.

Recently, our group demonstrated the effectiveness of oral estrogen therapy in the treatment of psychopathological symptoms in males with schizophrenia (112). These findings corroborate an earlier pilot study of estrogen therapy in men with schizophrenia, as well as reports of a reduction in depressive, aggressive, anxiety and psychotic symptoms in elderly men and women with dementia when treated with estrogen (113-115). These findings highlight the therapeutic efficacy that estrogen may entail for mental illnesses characterised by cognitive and mood dysfunction. However, further research is needed to explicitly examine its role in the treatment of severe mental illnesses in men.

\section{Concerns Regarding the Use of Estradiol in Men}

Use of estradiol in men is limited by side effects, particularly feminisation. The dose used for the development of female secondary sexual characteristics in male to female transsexuals is $2-4 \mathrm{mg}$ of oral estradiol valerate (or transdermal E2) (116) combined with potent antiandrogen therapy. In contrast, studies assessing the use of estradiol in psyhiatric illness use in the order of $1 \mathrm{mg}$ estradiol and no antiandrogen therapy.

In psychiatric studies using lower doses of estrogen over short periods of time side effects leading to withdrawal from the trials have included nausea, headaches and gynecomastia, (117) symptoms similar to those that cause cessation of hormone therapy in women.

The risk of venous thrombosis is another concern of long term use of estrogen therapy. Oral estrogen therapy is known to increase the risk of deep vein thrombosis in pre and post menopausal women, via increased production of clotting factors by the liver, due to first pass metabolism. In fact, estrogen therapy has been used to treat bleeding problems in both men and women with renal failure and other disorders (118). The Women's Health Initiative found that combined estrogen and progestin therapy double the risk of venous thromboemolism (VTE), whilst oral estrogen only therapy increased the risk by $32 \%$ in postmenopausal women (119). Transdermal estradiol however, does not appear to increase the risk of venous thromboembolism in postmenopausal women (120). The oral contraceptive pill increases the risk of VTE by more than two fold in women between $15-44$ years old, (121) though the level of risk varies with the progestin used.

Whether estrogen therapy in men could increase rates 
of hormone dependent cancer is another concern. In a Dutch study, 966 male to female transsexual men from one gender dysphoria clinic were followed up after a median of 18.5 years (116). While overall mortality was increased compared with the general population, through increased deaths related to suicide, drugs, AIDS and cardiovascular disease, there was no increase in the overall rate of cancer mortality. No cases of breast cancer were observed (116). This is reassuring although the results are not generalisable to other populations and the group size prevents the detection of small increases in risk (as in the Womens Health Study).

Estrogen plays a key role in male fertility. Circulating estrogens as well as locally produced estrogen (from aromatization of testosterone in local tissues) suppresses gonadotrophin releasing hormone $(\mathrm{GnRH})$ at the level of the hypothalamus and pituitary (119) Administration of aromatase inhibitors to adult men (with a resultant decrease in estradiol and increase in testosterone) results in raised LH and FSH. Chronic low dose estrogen therapy for schizophrenia could therefore result in hypogonadotrophic hypogonadism, with potentially lower serum testosterone levels.

Whether estrogens play a role in spermatogenesis is not understood. Concerns have been raised that the decline in human fertility in developed societies in recent decades may be attributable to exposure to xeno-estrogens (120).

Selective estrogen receptor modulators (SERMs) are compounds that can have both estrogen receptor agonist and antagonist actions. The hope is that these agents will be able to provide men with the benefits of estrogen in the brain without the peripheral feminizing effects.

In large studies of the SERM raloxifene in women, an increased risk of venous thromboembolism and fatal stroke has been found (122-124). These studies used doses of $60 \mathrm{mg}$ orally, half the dose required for a therapeutic effect in schizophrenia.

The risks of estrogen and SERM therapy in men is largely unknown. In our studies we are particularly vigilant for signs of feminisation, and venous thromboembolism. In the longer term, we will need to examine the potential effects on fertility and stroke risk. Ischaemic stroke has been associated with estrogen therapies in women, including the combined oral contraceptive pill,(125) tibolone (a hormone like therapy), (126) post menopausal hormone therapy (127) and raloxifene (128). This is of particular concern in the treatment of schizophrenia as the rates of stroke risk factors such as smoking are considerably high in men and women with schizophrenia (129).

\section{Selective Estrogen Receptor Modulators}

SERMs are a class of compounds that includes the commonly used drugs raloxifene and tamoxifen and newer agents such as bazedoxifene and lasofoxifene. Raloxi- fene hydrochloride is a SERM, that acts as a tissue specific estrogen receptor agonist or antagonist (130). It is a benzothiophene derivative, and is distinguished from SERM compounds of the triphenylethylene class, including tamoxifen and toremifene, by its lack of endometrial stimulation (131). Like other drugs of its class, it is also antiproliferative in the breast (122) and prevents bone loss due to its agonist estrogenic action in bone (132). Most importantly, raloxifene has agonist actions in the brain similar to those of natural estrogen, offering positive estrogenic effects on neurotransmitter and neuronal systems (133). It appears to influence multiple neurotransmitter pathways being able to cross the blood-brain barrier in sufficient quantities to have a measurable effect in humans. Some of the neurotransmitter systems that may be influenced by raloxifene include serotonergic and dopaminergic systems in the frontal cortex, striatum and basal ganglia (134), brain areas commonly altered in people with schizophrenia (135). The SERMs appear to have an estradiol-like effect on brain neurochemistry, but without the adverse impact on breast and uterine tissue. We are currently conducting a large study using the SERM raloxifene as an adjunctive treatment in women with schizophrenia and our early, promising results have been published (136). SERMs have more targeted central nervous system actions, with minimal actions on estrogen receptors in breast or other sex organ tissue (137). Clinical use of SERMs may therefore enable improved targeting of activity in key brain regions associated with positive and negative psychotic symptoms without the risk of feminizing side effects.

The effects of raloxifene on brain function are still under investigation, and likely to be complex. Animal studies have suggested that raloxifene demonstrates estrogenlike beneficial effects on cholinergic transmission within the hippocampus (138), lending support for raloxifene to potentially improve aspects of cognitive function in particular. Of the few studies to explore the cognitive enhancing effects of raloxifene, the results of the MORE trial (5386 postmenopausal women with osteoporosis) found that compared to placebo, raloxifene at a dose of $120 \mathrm{mg} /$ day, but not $60 \mathrm{mg} /$ day, resulted in a reduced risk of developing mild cognitive impairment in post menopausal women (139). Data from smaller randomised trials have demonstrated slight improvements in verbal memory performance after one month of raloxifene (120 mg/day) treatment in postmenopausal women with osteoporosis (140), and after 12 weeks of raloxifene (120 mg/day) treatment in women with Alzheimer's disease (141).

A study on the effect of raloxifene on cognition in healthy, postmenopausal women found a slight increase in verbal memory performance after one month of high dose treatment, while no other differences were found after 12 months of treatment (140). A recent cognition and estrogen study showed a positive correlation be- 
tween improved cognition and higher estrogen levels (142). Yaffe et al. (2005) trialled two doses of raloxifene (60 mg oral per day and $120 \mathrm{mg}$ oral per day) vs. placebo in postmenopausal women with normal cognition, mild cognitive impairment and Alzheimer's disease (139). The women receiving $120 \mathrm{mg}$ raloxifene per day had better cognitive outcomes compared to the $60 \mathrm{mg}$ raloxifene per day group or the placebo group.

\section{Conclusions}

Schizophrenia is a serious and debilitating disease with significant social and economic costs to the individual, their family and society. New treatment approaches are needed to improve patients' quality of life and functioning above the current outcomes seen with existing treatments. Innovative adjunctive hormone therapies, such as estradiol and SERMs, may offer new opportunities to achieve improved outcomes in a broad population of individuals with schizophrenia. The development of nonfeminising estrogens, SERMs, opens up a potentially new and safe treatment strategy for men suffering under the considerable burden of schizophrenia. Further research is needed to assess the efficacy of short term estradiol or SERMs. Longer term trials may be possible with SERMs. Increasing the affinity of SERMs for estrogen receptors in the brain should increase the effectiveness of such strategies.

\section{Acknowledgments}

None declared.

\section{Authors' Contribution}

All authors contributed to the literature review and the writing of the manuscript.

\section{Financial Disclosure}

None of the authors have any financial conflicts to disclose.

\section{Funding/Support}

Nil specific funding for this article, No sponsor.

\section{References}

1. Diagnostic and Statistical Manual of Mental Disorders, Fourth Edition: DSM-IV-TR. American Psychiatric Association; 2000.

2. Jablensky AV, McGrath J, Herrman H, Castle D, Gureje O, Evans M. Psychotic disorders in urban areas: an overview of the Study on Low Prevalence Disorders. Aust N Z J Psychiatry. [Research Support, Non-U.S. Gov't]. 2000;34(2):221-36.

3. Carr Vaughan J, Neil Amanda L, Halpin Sean A, Holmes Scott, Lewin Terry J. Costs of schizophrenia and other psychoses in urban Australia: findings from the Low Prevalence (Psychotic) Disorders Study. Australas Psychiat. 2003;37(1):31-40.

4. Kraepelin E. Psychiatrie; ein Lehrbuch für Studierende und Ärzte. Barth; 1910.

5. Krafft-Ebing G. Untersuchungen über Irresein zur Zeit der Men- struation: ein klinischer Beitrag zur Lehre vom periodischen Irresein. Arch Psychiatry. 1896;8:65-107.

6. Häfner Heinz. Gender differences in schizophrenia. Psychoneuroendocrinology. 2003;28:17-54

7. Kulkarni Jayashri. Women and schizophrenia: a review. Australas Psychiat. 1997;31(1):46-56.

8. Riecher-Rössler Anita, Häfner Heinz. Schizophrenia and oestrogens-is there an association? Eur Arch Psy Clin N. 1993;242(6):323328.

9. Seeman Mary V, Lang Marisa. The role of estrogens in schizophrenia gender differences. Schizophrenia Bull.1990;16(2):185-194.

10. Akhondzadeh Shahin, Nejatisafa Ali Akbar, Amini Homayoun, Mohammadi Mohammad Reza, Larijani Bagher, Kashani Ladan, et al. Adjunctive estrogen treatment in women with chronic schizophrenia: a double-blind, randomized, and placebo-controlled trial. Prog Neuro-Psychopha Bio Psychiatry . 2003;27(6):1007-1012.

11. Kulkarni J, de Castella A, Fitzgerald PB, Gurvich CT, Bailey M, Bartholomeusz C, et al. Estrogen in severe mental illness: a potential new treatment approach. Arch Gen Psychiatry. 2008;65(8):955-60.

12. Kulkarni J, Gavrilidis E, Worsley R, Hayes E. Role of estrogen treatment in the management of schizophrenia. CNS Drugs. 2012;26(7):549-57.

13. McGrath J, Saha S, Chant D, Welham J. Schizophrenia: a concise overview of incidence, prevalence, and mortality. Epidemiol Rev. 2008;30:67-76.

14. Perala J, Suvisaari J, Saarni SI, Kuoppasalmi K, Isometsa E, Pirkola $\mathrm{S}$, et al. Lifetime prevalence of psychotic and bipolar I disorders in a general population. Arch Gen Psychiatry. 2007;64(1):19-28.

15. Aleman A, Kahn RS, Selten JP. Sex differences in the risk of schizophrenia: evidence from meta-analysis. Arch Gen Psychiatry. 2003;60(6):565-71.

16. McGrath J, Saha S, Welham J, El Saadi O, MacCauley C, Chant D. A systematic review of the incidence of schizophrenia: the distribution of rates and the influence of sex, urbanicity, migrant status and methodology. BMCMed. 2004;2:13.

17. Angermeyer Matthias C, Kühnz Ludwig. Gender differences in age at onset of schizophrenia. Eur Arch Psy Neurol Sci. 1988;237(6):351-364

18. Faraone SV, Chen WJ, Goldstein JM, Tsuang MT. Gender differences in age at onset of schizophrenia. BrJPsychiatry. 1994;164(5):625-9.

19. Bergemann N, Parzer P, Runnebaum B, Resch F, Mundt C. Estrogen, menstrual cycle phases, and psychopathology in women suffering from schizophrenia. Psychol Med. 2007;37(10):1427-36.

20. Rubin LH, Carter CS, Drogos L, Pournajafi-Nazarloo H, Sweeney JA, Maki PM. Peripheral oxytocin is associated with reduced symptom severity in schizophrenia. Schizophr Res. 2010;124(13):13-21.

21. Hafner H, Nowotny B, Loffler W, an der Heiden W, Maurer K. When and how does schizophrenia produce social deficits? Eur Arch Psychiatry Clin Neurosci. 1995;246(1):17-28.

22. Cotton SM, Lambert M, Schimmelmann BG, Foley DL, Morley KI, McGorry PD, et al. Gender differences in premorbid, entry, treatment, and outcome characteristics in a treated epidemiological sample of 661 patients with first episode psychosis. Schizophr Res. 2009;114(1-3):17-24.

23. Beratis S, Gabriel J, Hoidas S. Age at onset in subtypes of schizophrenic disorders. Schizophr Bull.1994;20(2):287-96.

24. Goldstein Jill M, Link Bruce G. Gender and the expression of schizophrenia. J Psychiat Res. 1988;22(2):141-155.

25. Dopfner M, Pluck J, Berner W, Fegert JM, Huss M, Lenz K, et al. [Mental disturbances in children and adolescents in Germany. Results of a representative study:age,gender and rater effects]. Z Kinder Jugendpsychiatr Psychother. 1997;25(4):218-33.

26. Morgan VA, Castle DJ, Jablensky AV. Do women express and experience psychosis differently from men? Epidemiological evidence from the Australian National Study of Low Prevalence (Psychotic) Disorders. Aust N Z J Psychiatry. 2008;42(1):74-82.

27. Gómez-de-Regil Lizzette, Kwapil Thomas R, Blanqué Joan Manel, Vainer Elias, Montoro Mónica, Barrantes-Vidal Neus. Predictors of outcome in the early course of first-episode psychosis. Eur J 
Psychiat. 2010;24(2):87-97.

28. Cosimo Melcangi R, Garcia-Segura LM. Sex-specific therapeutic strategies based on neuroactive steroids: In search for innovative tools for neuroprotection. Horm Behav. 2010;57(1):2-11.

29. McEwen BS. Invited review: Estrogens effects on the brain: multiple sites and molecular mechanisms. J Appl Physiol. 2001;91(6):2785-801.

30. Schiff R, Bulpitt CJ, Wesnes KA, Rajkumar C. Short-term transdermal estradiol therapy, cognition and depressive symptoms in healthy older women. A randomised placebo controlled pilot cross-over study. Psychoneuroendocrinology. 2005;30(4):309-15.

31. Carranza-Lira S, Valentino-Figueroa ML. Estrogen therapy for depression in postmenopausal women. Int I Gynecol Obstet. 1999;65(1):35-38.

32. Schmidt PJ, Nieman L, Danaceau MA, Tobin MB, Roca CA, Murphy $\mathrm{JH}$, et al. Estrogen replacement in perimenopauserelated depression: a preliminary report. Am J Obstet Gynecol. 2000;183(2):414-20.

33. Wharton W, Baker LD, Gleason CE, Dowling M, Barnet JH, Johnson $\mathrm{S}$, et al. Short-term hormone therapy with transdermal estradio improves cognition for postmenopausal women with Alzheimer's disease: results of a randomized controlled trial. J Alzheimers Dis. 2011;26(3):495-505.

34. Yonker JE, Adolfsson R, Eriksson E, Hellstrand M, Nilsson LG, Herlitz A. Verified hormone therapy improves episodic memory performance in healthy postmenopausal women. Neuropsychol Dev Cogn B Aging Neuropsychol Cogn. 2006;13(3-4):291-307.

35. Österlund Marie K, Hurd Yasmin L. Estrogen receptors in the human forebrain and the relation to neuropsychiatric disorders Prog Neurobiol. 2001;64(3):251-267.

36. Roberts Angela C, Robbins Trevor W, Weiskrantz Lawrence. The prefrontal cortex Executive and cognitive functions. Hogrefe and Huber; 1998.

37. Gonzalez M, Cabrera-Socorro A, Perez-Garcia CG, Fraser JD, Lopez FJ, Alonso R, et al. Distribution patterns of estrogen receptor alpha and beta in the human cortex and hippocampus during development and adulthood. J Comp Neurol. 2007;503(6):790-802.

38. Litwack G. Hormones of the Limbic System. Elsevier Science; 2010.

39. Fink G, Sumner BE, Rosie R, Grace O, Quinn JP. Estrogen control of central neurotransmission: effect on mood, mental state, and memory. Cell Mol Neurobiol.1996;16(3):325-44.

40. Hafner H, Behrens S, De Vry J, Gattaz WF. Oestradiol enhances the vulnerability threshold for schizophrenia in women by an early effect on dopaminergic neurotransmission. Evidence from an epidemiological study and from animal experiments. Eur Arch Psychiatry Clin Neurosci. 1991;241(1):65-8.

41. Halbreich Uriel, Rojansky Nathan, Palter Steven, Tworek Henry, Hissin Paul, Wang Ke. Estrogen augments serotonergic activity in postmenopausal women. Biological psychiatry. 1995;37(7):434 441.

42. Halbreich U, Kahn LS. Role of estrogen in the aetiology and treatment of mood disorders. CNS Drugs. 2001;15(10):797-817.

43. Halbreich Uriel. Role of estrogen in postmenopausal depression. Neurology. 1997; 48(5 Suppl 7):16S-20S.

44. Hiroi Ryoko, McDevitt Ross A, Neumaier John F. Estrogen selectively increases tryptophan hydroxylase-2 mRNA expression in distinct subregions of rat midbrain raphe nucleus: association between gene expression and anxiety behavior in the open field. Biol Psychiat. 2006;60(3):288-295.

45. Bethea Cynthia L, Mirkes Stephanie J, Shively Carol A, Adams Michael R. Steroid regulation of tryptophan hydroxylase protein in the dorsal raphe of macaques. Biol Psychiat. 2000;47(6):562.

46. Pecins-Thompson M, Brown NA, Kohama SG, Bethea CL. Ovarian steroid regulation of tryptophan hydroxylase mRNA expression in rhesus macaques. J Neurosci. 1996;16(21):7021-9.

47. Ivanova $\mathrm{T}$, Beyer $\mathrm{C}$. Estrogen regulates tyrosine hydroxylase expression in the neonate mouse midbrain. J Neurobiol. 2003;54(4):638-47.

48. Sawada Hideyuki, Ibi Masakazu, Kihara Takeshi, Honda Kazuhiro, Nakamizo Tomoki, Kanki Rie, et al. Estradiol protects dopaminergic neurons in a MPP+ Parkinson's disease model. Neurophar- macology. 2002:42(8):1056-1064.

49. Lyons Kelly E, Hubble Jean P, Tröster Alexander I, Pahwa Rajesh, Koller William C. Gender differences in Parkinson's disease. Clinical neuropharmacology. 1998;21(2):118-121.

50. Wolfe Nicola, Katz DI, Albert ML, Almozlino A, Durso R, Smith MC et al. Neuropsychological profile linked to low dopamine: in Alzheimer's disease, major depression, and Parkinson's disease. Neurol Neurosurgery Psychiat. 1990;53(10):915-917.

51. Wharton Whitney, Baker Laura D, Gleason Carey E, Dowling Maritza, Barnet Jodi H, Johnson Sterling, et al. Short-term hormone therapy with transdermal estradiol improves cognition for postmenopausal women with Alzheimer's disease: results of a randomized controlled trial. JAlz Dis. 2011;26(3):495-505.

52. Henderson Victor W, Paganini-Hill Annlia, Emanuel Christina K, Dunn Meleana E, Buckwalter J Galen. Estrogen replacement therapy in older women: comparisons between Alzheimer's disease cases and nondemented control subjects. Arch Neurol. 1994;51(9):896.

53. Fernandez Hubert H, Lapane Kate L. Estrogen use among nursing home residents with a diagnosis of Parkinson's disease. Movement disorders. 2000;15(6):1119-1124.

54. Saunders-Pullman R, Gordon-Elliott J, Parides M, Fahn S, Saunders HR, Bressman $S$. The effect of estrogen replacement on early Parkinson's disease. Neurology. 1999;52(7):1417-1417.

55. Tang Ming-Xin, Jacobs Diane, Stern Yaakov, Marder Karen, Schofield Peter, Gurland Barry, et al. Effect of oestrogen during menopause on risk and age at onset of Alzheimer's disease. The Lancet. 1996;348(9025):429-432.

56. Paganini-Hill Annlia, Henderson Victor W. Estrogen deficiency and risk of Alzheimer's disease in women. Am J Epidemiol. 1994;140(3):256-261.

57. Yue X, Lu M, Lancaster T, Cao P, Honda S, Staufenbiel M, et al Brain estrogen deficiency accelerates Abeta plaque formation in an Alzheimer's disease animal model. Proc Natl Acad Sci U S A 2005;102(52):19198-203.

58. Kawas Claudia, Resnick S, Morrison AMRC, Brookmeyer R, Corrada $\mathrm{M}$, Zonderman $\mathrm{A}$, et al. A prospective study of estrogen replacement therapy and the risk of developing Alzheimer's disease The Baltimore Longitudinal Study of Aging. Neurology. 1997;48(6):1517-1521.

59. Hampson Elizabeth. Estrogen-related variations in human spatial and articulatory-motor skills. Psychoneuroendocrinology. 1990;15(2):97-111

60. Kulkarni J. Oestrogen-a new treatment approach for schizophrenia? Med J Aust. 2009;190(4 Suppl):S37-8.

61. Halbreich U, Kahn LS. Hormonal aspects of schizophrenias: an overview. Psychoneuroendocrinology. 2003;28:1-16.

62. Kulkarni J, Riedel A, De Castella AR, Fitzgerald PB, Rolfe TJ, Taffe J, et al. Estrogen-a potential treatment for schizophrenia. Schizophr Res. 2001;48(1):137-144.

63. Kulkarni Jayashri, Garland Kathryn A, Scaffidi Antonietta, Headey Barbara, Anderson Robyn, de Castella Anthony, et al. A pilo study of hormone modulation as a new treatment for mania in women with bipolar affective disorder. Psychoneuroendocrinol ogy. 2006;31(4):543.

64. Hafner H, Behrens S, De Vry J, Gattaz WF. Oestradiol enhances the vulnerability threshold for schizophrenia in women by an early effect on dopaminergic neurotransmission: evidence from an epidemiological study and from animal experiments. Eur Arch Psy Cin Neurosci 1991;241(1):65-68.

65. Häfner Heinz, an der Heiden Wolfram, Behrens Stephan, Gattaz Wagner F, Hambrecht Martin, Löffler Walter, et al. Causes and consequences of the gender difference in age at onset of schizophrenia. Schizophrenia Bull.1998;24(1):99-113.

66. Seeman P. Dopamine receptors and the dopamine hypothesis of schizophrenia. Synapse.1987;1(2):133-52.

67. Berk M, Dodd S, Kauer-Sant'anna M, Malhi GS, Bourin M, Kapczinski F, et al. Dopamine dysregulation syndrome: implications for a dopamine hypothesis of bipolar disorder. Acta Psychiatr Scand Suppl. 2007;(434):41-9.

68. Mahmood Tariq, Silverstone Trevor. Serotonin and bipolar disor- 
der.J Affect Disorders. 2001;66(1):1-11.

69. Goodwin FK, Jamison KR. Manic-Depressive Illness: Bipolar Disorders and Recurrent Depression. 2007.

70. Urosevic S, Abramson LY, Harmon-Jones E, Alloy LB. Dysregulation of the behavioral approach system (BAS) in bipolar spectrum disorders: review of theory and evidence. Clin Psychol Rev. 2008;28(7):1188-205.

71. Bora E, Yucel M, Pantelis C. Cognitive functioning in schizophrenia, schizoaffective disorder and affective psychoses: meta-analytic study. BrJ Psychiatry. 2009;195(6):475-82.

72. Green MF. Cognitive impairment and functional outcome in schizophrenia and bipolar disorder.J Clin Psychiatry. 2006;67(10) :ee12.

73. Green Michael Foster, Nuechterlein Keith H. Should schizophrenia be treated as a neurocognitive disorder? Schizophrenia Bull. 1999;25(2):309-319.

74. Hooker C, Park S. Emotion processing and its relationship to social functioning in schizophrenia patients. Psychiatry Res. 2002;112(1):41-50

75. Getz GE, Shear PK, Strakowski SM. Facial affect recognition deficits in bipolar disorder. JInt Neuropsychol Soc. 2003;9(4):623-32.

76. Riecher-Rossler A, Hafner H, Stumbaum M, Maurer K, Schmidt R. Can estradiol modulate schizophrenic symptomatology? Schizophr Bull.1994;20(1):203-14.

77. Ko YH, Joe SH, Cho W, Park JH, Lee JJ, Jung IK, et al. Estrogen, cognitive function and negative symptoms in female schizophrenia. Neuropsychobiology. 2006;53(4):169-75.

78. Hoff AL, Kremen WS, Wieneke MH, Lauriello J, Blankfeld HM, Faustman WO, et al. Association of estrogen levels with neuropsychological performance in women with schizophrenia. Am J Psychiatry. 2001;158(7):1134-9.

79. Hogervorst Eva, De Jager Celeste, Budge Marc, Smith A David. Serum levels of estradiol and testosterone and performance in different cognitive domains in healthy elderly men and women. Psychoneuroendocrinology. 2004;29(3):405-421.

80. Senanarong V, Vannasaeng S, Poungvarin N, Ploybutr S, Udompunthurak S, Jamjumras P, et al. Endogenous estradiol in elderly individuals: cognitive and noncognitive associations. Arch Neurol. 2002;59(3):385-9.

81. Yaffe K, Barnes D, Lindquist K, Cauley J, Simonsick EM, Penninx $\mathrm{B}$, et al. Endogenous sex hormone levels and risk of cognitive decline in an older biracial cohort. Neurobiol Aging. 2007;28(2):171178.

82. Kampen Diane L, Sherwin Barbara B. Estradiol is related to visual memory in healthy young men. Behav Neurosci 1996;110(3):613.

83. E Carlson Linda, B Sherwin Barbara. Steroid hormones, memory and mood in a healthy elderly population. Psychoneuroendocrinology. 1998;23(6):583-603

84. Geerlings MI, Launer LJ, de Jong FH, Ruitenberg A, Stijnen T, van Swieten JC, et al. Endogenous estradiol and risk of dementia in women and men: the Rotterdam Study. Ann Neurol. 2003;53(5):607-15

85. Young LA, Neiss MB, Samuels MH, Roselli CE, Janowsky JS. Cognition is not modified by large but temporary changes in sex hormones in men. JClin Endocrinol Metab. 2010;95(1):280-8.

86. Geerlings MI, Strozyk D, Masaki K, Remaley AT, Petrovitch H, Ross $\mathrm{GW}$, et al. Endogenous sex hormones, cognitive decline, and future dementia in old men. Ann Neurol. 2006;60(3):346-55.

87. Janowsky JS, Chavez B, Orwoll E. Sex steroids modify working memory.J Cogn Neurosci. 2000;12(3):407-14.

88. Almeida OP, Yeap BB, Hankey GJ, Jamrozik K, Flicker L. Low free testosterone concentration as a potentially treatable cause of depressive symptoms in older men. Arch Gen Psychiatry. 2008;65(3):283-9.

89. Zitzmann M, Faber S, Nieschlag E. Association of specific symptoms and metabolic risks with serum testosterone in older men JClin Endocrinol Metab. 2006;91(11):4335-43.

90. Shores MM, Sloan KL, Matsumoto AM, Moceri VM, Felker B, Kivlahan DR. Increased incidence of diagnosed depressive illness in hypogonadal older men. Arch Gen Psychiatry. 2004;61(2):162-7.

91. Seidman SN, Araujo AB, Roose SP, Devanand DP, Xie S, Cooper TB, et al. Low testosterone levels in elderly men with dysthymic disorder. Am J Psychiatry. 2002;159(3):456-9.

92. Beauchet $O$. Testosterone and cognitive function: current clinical evidence of a relationship. Eur JEndocrinol. 2006;155(6):773-81.

93. Beer Tomasz M, Bland Lisa B, Bussiere Joseph R, Neiss Michelle B, Wersinger Emily M, Garzotto Mark, et al. Testosterone loss and estradiol administration modify memory in men. J Urology. 2006;175(1):130-135.

94. Wang Christina, Cunningham Glenn, Dobs Adrian, Iranmanesh Ali, Matsumoto Alvin M, Snyder Peter J, et al. Long-term testosterone gel (AndroGel) treatment maintains beneficial effects on sexual function and mood, lean and fat mass, and bone mineral density in hypogonadal men. J Clin Endocr Metab. 2004;89(5):2085-2098.

95. Cherrier MM, Asthana S, Plymate S, Baker L, Matsumoto AM, Peskind $\mathrm{E}$, et al. Testosterone supplementation improves spatial and verbal memory in healthy older men. Neurology. 2001;57(1):80-8.

96. Hammond J, Le Q, Goodyer C, Gelfand M, Trifiro M, LeBlanc A. Testosterone-mediated neuroprotection through the androgen receptor in human primary neurons. J Neurochem. 2001;77(5):131926.

97. Tan RS, Pu SJ. A pilot study on the effects of testosterone in hypogonadal aging male patients with Alzheimer's disease. Aging Male. 2003;6(1):13-7.

98. Fernandez-Egea Emilio, García-Rizo Clemente, Miller Brian, Parellada Eduard, Justicia Azucena, Bernardo Miguel, et al. Testosterone in newly diagnosed, antipsychotic-naive men with nonaffective psychosis: a test of the accelerated aging hypothesis. Psychosom Med. 2011;73(8):643-647.

99. Cherrier MM, Aubin S, Higano CS. Cognitive and mood changes in men undergoing intermittent combined androgen blockade for non-metastatic prostate cancer. Psycho Oncology. 2009;18(3):237-247

100. Almeida Osvaldo P, Waterreus Anna, Spry Nigel, Flicker Leon, Martins Ralph N. One year follow-up study of the association between chemical castration, sex hormones, beta-amyloid, memory and depression in men. Psychoneuroendocrinology. 2004;29(8):1071-1081.

101. Kenny AM, Bellantonio S, Gruman CA, Acosta RD, Prestwood KM. Effects of transdermal testosterone on cognitive function and health perception in older men with low bioavailable testosterone levels. J Gerontol A Biol Sci Med Sci. 2002;57(5):M321-5.

102. Oberlander Joseph G, Schlinger Barney A, Clayton Nicola S, Saldanha Colin J. Neural aromatization accelerates the acquisition of spatial memory via an influence on the songbird hippocampus. Horm Behav. 2004;45(4):250-258.

103. Naghdi Nasser, Oryan Shahrbanoo, Etemadi Roshanak. The study of spatial memory in adult male rats with injection of testosterone enanthate and flutamide into the basolateral nucleus of the amygdala in Morris water maze. Brain research. 2003;972(1):1-8

104. Fink George, Sumner Barbara, Rosie Roberta, Wilson Helen, McQueen Judith. Androgen actions on central serotonin neurotransmission: relevance for mood, mental state and memory. Behav Brain Res. 1999;105(1):53.

105. Cherrier MM, Matsumoto AM, Amory JK, Ahmed S, Bremner W, Peskind ER, et al. The role of aromatization in testosterone supplementation: effects on cognition in older men. Neurology. 2005;64(2):290-6.

106. Wolf Oliver T, Kirschbaum Clemens. Endogenous estradiol and testosterone levels are associated with cognitive performance in older women and men. Horm Behav. 2002;41(3):259-266.

107. Miles Clare, Green Richard, Sanders Geoff, Hines Melissa. Estrogen and memory in a transsexual population. Horm Behav. 1998;34(2):199-208.

108. Carlson Linda E, Sherwin Barbara B, Chertkow Howard M. Relationships Between Mood and Estradiol (E 2) Levels in Alzheimers's Disease (AD) Patients. J Gerontol Ser B. 2000;55(1):P47-P53.

109. Ockrim JL, Lalani EN, Laniado ME, Carter SS, Abel PD. Transderma estradiol therapy for advanced prostate cancer--forward to the past? JUrol. 2003;169(5):1735-7.

110. Spetz Anna-Clara, Hammar Mats, Lindberg Bengt, Spångberg An- 
ders, Varenhorst Eberhard. Prospective evaluation of hot flashes during treatment with parenteral estrogen or complete androgen ablation for metastatic carcinoma of the prostate. J Urol. 2001;166(2):517-520.

111. Hedlund Per Olov, Henriksson Peter. Parenteral estrogen versus total androgen ablation in the treatment of advanced prostate carcinoma: effects on overall survival and cardiovascular mortality. Urology. 2000;55(3):328-332.

112. Kulkarni J, de Castella A, Headey B, Marston N, Sinclair K, Lee S, et al. Estrogens and men with schizophrenia: is there a case for adjunctive therapy? Schizophr Res. 2011;125(2-3):278-83.

113. Kyomen HH, Hennen J, Gottlieb GL, Wei JY. Estrogen therapy and noncognitive psychiatric signs and symptoms in elderly patients with dementia. Am J Psychiatry. 2002;159(7):1225-7.

114. Kyomen HH, Satlin A, Hennen J, Wei JY. Estrogen therapy and aggressive behavior in elderly patients with moderate-to-severe dementia: results from a short-term, randomized, double-blind trial. Am J Geriatr Psychiatry. 1999;7(4):339-48.

115. Kulkarni J, De Castella A, Taffe J. Clinical adjunctive estrogen trial in men with schizophrenia: a pilot study. Schizophr Res. 1999;36:286

116. Asscheman H, Giltay EJ, Megens JA, de Ronde WP, van Trotsenburg MA, Gooren LJ. A long-term follow-up study of mortality in transsexuals receiving treatment with cross-sex hormones. Eur Endocrinol. 2011;164(4):635-42.

117. Sherwin Barbara B, Chertkow Howard, Schipper Hyman, Nasreddine Ziad. A randomized controlled trial of estrogen treatment in men with mild cognitive impairment. Neurobiol Aging. 2011;32(10):1808-1817.

118. Livio M, Mannucci PM, Vigano G, Mingardi G, Lombardi R, Mecca $\mathrm{G}$, et al. Conjugated estrogens for the management of bleeding associated with renal failure. N EnglJ Med. 1986;315(12):731-5.

119. Hayes FJ, Seminara SB, Decruz S, Boepple PA, Crowley WF, Jr. Aromatase inhibition in the human male reveals a hypothalamic site of estrogen feedback. J Clin Endocrinol Metab. 2000;85(9):3027-35.

120. Comhaire FH, Dhooge W, Mahmoud A, Depuydt C. [A strategy for the prevention of male infertility]. Verh K Acad Geneeskd Belg. 1999;61(3):441-52.

121. Lidegaard Øjvind, Løkkegaard Ellen, Svendsen Anne Louise, Agger Carsten. Hormonal contraception and risk of venous thromboembolism: national follow-up study. BMJ. 2009;339.

122. Cummings SR, Eckert S, Krueger KA, Grady D, Powles TJ, Cauley JA, et al. The effect of raloxifene on risk of breast cancer in postmenopausal women: results from the MORE randomized trial. Multiple Outcomes of Raloxifene Evaluation. JAMA. 1999;281(23):2189-97.

123. Mosca L. Rationale and overview of the Raloxifene Use for the Heart (RUTH) trial. Ann N Y Acad Sci. 2001;949:181-5.

124. Vogel Victor G, Costantino Joseph P, Wickerham D Lawrence, Cronin Walter M, Wolmark Norman. The study of tamoxifen and raloxifene: preliminary enrollment data from a randomized breast cancer risk reduction trial. Clinical breast cancer. 2002;3(2):153-159.

125. Lidegaard Øjvind, Løkkegaard Ellen, Jensen Aksel, Skovlund Charlotte Wessel, Keiding Niels. Thrombotic stroke and myocardial infarction with hormonal contraception. New EnglJMed. 2012;366(24):2257-2266.

126. Cummings Steven R, Ettinger Bruce, Delmas Pierre D, Kenemans Peter, Stathopoulos Victoria, Verweij Pierre, et al. The effects of tibolone in older postmenopausal women. New Engl J Med. 2008;359(7):697-708

127. Henderson VW, Lobo RA. Hormone therapy and the risk of stroke: perspectives 10 years after the Women's Health Initiative trials. Climacteric. 2012;15(3):229-234.

128. Messalli EM, Scaffa C. Long-term safety and efficacy of raloxifene in the prevention and treatment of postmenopausal osteoporosis: an update. Int JWomens Health. 2010;1:11-20.

129. Cooper J, Mancuso SG, Borland R, Slade T, Galletly C, Castle D. Tobacco smoking among people living with a psychotic illness: the second Australian Survey of Psychosis. Aust N Z J Psychiatry. 2012;46(9):851-63.

130. Mitlak BH, Cohen FJ. In search of optimal long-term female hormone replacement: the potential of selective estrogen receptor modulators. Horm Res Paediatr. 2008;48(4):155-163.

131. Goldstein Steven R, Scheele Wim H, Rajagopalan Srikanth K, Wilkie Jennifer L, Walsh Brian W, Parsons Anna K. A 12-month comparative study of raloxifene, estrogen, and placebo on the postmenopausal endometrium. Obstetrics and Gynecology. 2000;95(1):95-103.

132. Ettinger B, Black DM, Mitlak BH, Knickerbocker RK, Nickelsen $\mathrm{T}$, Genant HK, et al. Reduction of vertebral fracture risk in postmenopausal women with osteoporosis treated with raloxifene: results from a 3-year randomized clinical trial. Multiple Outcomes of Raloxifene Evaluation (MORE) Investigators. JAMA 1999;282(7):637-45.

133. Huang Y, Huang YL, Lai B, Zheng P, Zhu YC, Yao T. Raloxifene acutely reduces glutamate-induced intracellular calcium increase in cultured rat cortical neurons via inhibition of high-voltage-activated calcium current. Neuroscience. 2007;147(2):334-41.

134. Littleton-Kearney MT, Ostrowski NL, Cox DA, Rossberg MI, Hurn PD. Selective estrogen receptor modulators: tissue actions and potential for CNS protection. CNS Drug Rev. 2002;8(3):309-30

135. Iritani S. Neuropathology of schizophrenia: a mini review. Neuropathology. 2007;27(6):604-8.

136. Kulkarni Jayashri, Gurvich Caroline, Lee Stuart J, Gilbert Heather, Gavrilidis Emmy, de Castella Anthony, et al. Piloting the effective therapeutic dose of adjunctive selective estrogen receptor modulator treatment in postmenopausal women with schizophrenia. Psychoneuroendocrinology. 2010;35(8):1142-1147.

137. Cyr M, Calon F, Morissette M, Di Paolo T. Estrogenic modulation of brain activity: implications for schizophrenia and Parkinson's disease.J Psychiatry Neurosci. 2002;27(1):12-27.

138. Wu Xin, Glinn Michele A, Ostrowski Nancy L, Su Yuan, Ni Binhui, Cole Harlan W, et al. Raloxifene and estradiol benzoate both fully restore hippocampal choline acetyltransferase activity in ovariectomized rats. Brain research. 1999;847(1):98-104.

139. Yaffe Kristine, Krueger Kathryn, Cummings Steven R, Blackwel Terri, Henderson Victor W, Sarkar Somnath, et al. Effect of raloxifene on prevention of dementia and cognitive impairment in older women: the Multiple Outcomes of Raloxifene Evaluation (MORE) randomized trial. Am J Psychiatry. 2005;162(4):683-690.

140. Nickelsen Thomas, G Lufkin Edward, Lawrence Riggs B, A Cox David, H Crook Thomas. Raloxifene hydrochloride, a selective estrogen receptor modulator: safety assessment of effects on cognitive function and mood in postmenopausal women. Psychoneuroendocrinology. 1999;24(1):115-128.

141. Gleason CE, Baker LD, Chlerton B, Craft S, Cherrier M, Lofgreen T. Effects of raloxifene on verbal memory in women with Alzheimer's disease. Abstracts of the Society for Neuroscience. Washington, DC: Society for Neuroscience; 2001. p. 1449

142. Asthana S. Estrogen and cognition: a true relationship? JAm Geriatr Soc. 2004;52(2):316-8.

Please cite this paper as: Kulkarni J, Gavrilidis E, Worsley R, Van Rheenen T, Hayes E. The Role of Estrogen in the Treatment of Men with Schizophrenia. Int J Endocrinol Metabol. 2013; 11(3):129-136. DOI: $10.5812 /$ ijem.6615 